\title{
Suppression of Hemostatic System Activation by Oral Anticoagulants in the Blood of Patients with Thrombotic Diatheses
}

\author{
Edward M. Conway, Kenneth A. Bauer, Samad Barzegar, and Robert D. Rosenberg \\ Charles A. Dana Research Institute and the Harvard-Thorndike Laboratory, Department of Medicine, Beth Israel Hospital and \\ Harvard Medical School, Boston, Massachusetts 02215; and the Department of Biology and Whitaker College, \\ Massachusetts Institute of Technology, Cambridge, Massachusetts 02139
}

\begin{abstract}
RIAs for hemostatic system activation were employed to study patients who were anticoagulated with warfarin. The mean prothrombin fragment $F_{1+2}$ concentration in stably anticoagulated individuals without an inherited thrombotic diathesis (mean prothrombin time [PT] ratio [PT of patient/PT of normal plasma pool] $=1.74$ ) was $0.231 \mathrm{nM}$ as compared with a mean plasma $F_{1+2}$ level of $1.68 \mathrm{nM}$ for a nonanticoagulated control group $(P<0.0001)$. The initiation of oral anticoagulants in two subjects who did not exhibit protein $\mathrm{C}$ deficiency led to a paradoxical increase in $\mathrm{F}_{1+2}$ levels during the first day of therapy. We have also shown that a relatively low intensity regimen of warfarin (PT ratio < 1.2 ) may reduce elevated concentrations of $F_{1+2}$ into the normal range in patients with a history of recurrent thromboembolism. The mean $F_{1+2}$ level in antithrombin-deficient individuals on warfarin was significantly elevated (mean $=0.714 \mathrm{nM}$ ) as compared with that in anticoagulated subjects with protein $C$ deficiency (mean $=0.205 \mathrm{nM})$ or in those without an inherited thrombotic disorder $(P<0.01)$ at equivalent levels of intensity of oral anticoagulation. We therefore conclude that the effect of warfarin on hemostatic system activation is modulated by the endogenous heparan sulfate-antithrombin mechanism.
\end{abstract}

\section{Introduction}

The conversion of prothrombin to thrombin is the central event in the coagulation of blood. This reaction takes place at an appreciable rate under physiologic conditions only in the presence of Factor Xa, Factor Va, calcium ions, and platelets. During this process, the amino terminus of the prothrombin molecule is released as the inactive $F_{1+2}$ fragment in conjunction with the generation of thrombin. Once produced, this serine protease is able to cleave two pairs of peptides, fibrinopeptides A (FPA) ${ }^{1}$ and B, from fibrinogen that permits the resulting fibrin to polymerize into an insoluble clot. Thrombin can also rapidly activate protein $\mathrm{C}$ by binding to thrombo-

This work was presented in part at the 28th Annual Meeting of the American Society of Hematology, San Francisco, CA, December 1986.

Address reprint requests to Dr. K. A. Bauer; Beth Israel Hospital, 330 Brookline Ave., Boston, MA 02215.

Received for publication 27 February 1987 and in revised form 7 July 1987.

1. Abbreviations used in this paper: asp, aspartic acid; FPA, fibrinopeptide A; gla, carboxyglutamic acid; $\mathrm{PCP}$, protein $\mathrm{C}$ activation peptide; PT, prothrombin time.

J. Clin. Invest.

(c) The American Society for Clinical Investigation, Inc. $0021-9738 / 87 / 12 / 1535 / 10 \quad \$ 2.00$

Volume 80, December 1987, 1535-1544 modulin on vascular endothelial cells at a 1:1 stoichiometric ratio of enzyme to receptor (1-3). The thrombin-thrombomodulin complex is then able to scission an $\mathrm{Arg}_{12}-\mathrm{Leu}_{13}$ bond at the amino-terminal end of the heavy chain of protein $\mathrm{C}$ that releases a small dodecapeptide of $M_{\mathrm{r}}$ of $\sim 1,400$ (4). Once generated, activated protein $\mathrm{C}$ can inhibit the platelet-dependent conversion of prothrombin to thrombin via Factor Xa by inactivating Factor VIIIa (5) and platelet-bound Factor Va (6). Protein $\mathrm{S}$ is able to enhance the binding of activated protein $\mathrm{C}$ to phospholipid-containing membranes and to accelerate the proteolytic inactivation of the two activated cofactors $(7,8)$. The enzymatic activity of thrombin can also be directly inhibited by the plasma protein antithrombin resulting in the formation of a stable enzyme-inhibitor complex. This interaction is accelerated by heparan sulfate proteoglycans associated with the vascular endothelium (9-11).

Based upon recent advances in our knowledge of the biochemistry of the coagulation system, a series of highly sensitive and specific immunoassays have been developed that can quantitate the activities of various steps of the hemostatic mechanism in vivo at the subnanomolar level. We have developed RIAs for the $\mathrm{F}_{1+2}$ fragment and the protein $\mathrm{C}$ activation peptide (PCP) that measure the cleavage of the prothrombin molecule by Factor $\mathrm{Xa}(12,13)$ and the scission of protein $\mathrm{C}$ by the thrombin-thrombomodulin complex (14), respectively. Nossel and co-workers $(15,16)$ had previously developed an immunoassay for FPA that monitors the proteolysis of fibrinogen by thrombin. All individuals exhibit measurable amounts of these markers. We have previously observed that substantial elevations in Factor Xa activity but not thrombin activity regularly occur in the blood of many individuals with hereditary deficiencies of antithrombin (17) and protein $\mathrm{C}^{2}$ In this communication, we have demonstrated that $F_{1+2}$ levels are markedly suppressed in stably anticoagulated patients receiving sodium warfarin, and that a relatively low intensity regimen of this medication may reduce elevated plasma levels of this fragment into the normal range in patients with a history of recurrent thromboembolism. We have also examined the effect of warfarin on this marker of hemostatic system activation in patients with deficiencies of antithrombin or protein C.

\section{Methods}

Collection and processing of blood samples. Venipunctures were performed atraumatically with 19- or 21-gauge butterfly infusion sets using a two-syringe technique. Blood samples were drawn into plastic syringes preloaded with the appropriate solutions as described below. These included: (a) For immunologic measurements of antithrombin,

2. Bauer, K. A., A. W. Broekmans, R. M. Bertina, J. Conard, M. Horellou, M. M. Samama, and R. D. Rosenberg, submitted for publication. 
protein $\mathrm{C}$, protein $\mathrm{S}$, and prothrombin, $3.8 \%$ (wt/vol) sodium citrate was employed; the ratio of anticoagulant to blood used was 0.1:0.9 (vol/vol). (b) "F $F_{1+2}$ and PCP anticoagulant:" (38 mM citric acid, 75 $\mathrm{mM}$ sodium citrate, $136 \mathrm{mM}$ dextrose, $6 \mathrm{mM}$ EDTA, $6 \mathrm{mM}$ adenosine, and $25 \mathrm{U} / \mathrm{ml}$ heparin; the ratio of anticoagulant to blood employed was 0.2:1.0 (vol/vol). (c) "FPA anticoagulant:" this preparation was provided by Mallinckrodt, Inc., St. Louis, MO; the ratio of anticoagulant to blood used was 0.1:0.9 (vol/vol). After collection of blood samples, plasma fractions were obtained by centrifugation at $4^{\circ} \mathrm{C}$ for $15 \mathrm{~min}$ at $1,600 \mathrm{~g}$ and stored at $-80^{\circ} \mathrm{C}$ before use.

A normal plasma pool was constructed by pooling equal volumes of plassma from 30 control subjects. This population consisted of healthy laboratory and medical personnel between the ages of 20 and $40 \mathrm{yr}$, who gave a negative history for bleeding as well as thrombosis, and were not taking any medications at the time of sample collection.

Coagulation studies. Routine coagulation studies including prothrombin time (PT) and activated partial thromboplastin time were performed by standard laboratory methods (18). In patients who were receiving vitamin $K$ antagonists; PTs were measured with rabbit brain thromboplastin (Automated Simplastin; Organon Teknika Corp., Durham, NC). The International Sensitivity Index of this reagent is $\sim 2$ 2.0. The intensity level of oral anticoagulation was expressed as the PT ratio (PT of patient/PT of normal plasma pool). An amidolytic assay for antithrombin-heparin cofactor activity employing the chromogenic substrate Tos-Gly-Pro-Arg-pNA (Chromozym TH; Boehringer Mannheim Biochemicals, Indianapolis, IN) was employed as previously described (19). The anticoagulant activity of protein $C$ was determined with a clotting method (Staclot Protein C; American Bioproducts Co., Parsippany, NJ).

The criteria of Bertina et al. were utilized to establish a laboratory diagnosis of a protein $\mathrm{C}(20)$ or protein $\mathrm{S}$ deficiency state (21).

Immunoassays. The plasma concentrations of protein $\mathrm{C}$, prothrombin, antithrombin, $\mathrm{F}_{1+2}$, and PCP were determined by double antibody RIA as described in earlier reports from our laboratory $(13,14,19)$. Antigenic levels of total protein $S$ were measured with an immunoradiometric assay technique (21). The plasma levels of FPA were established by RIA utilizing a kit provided by Mallinckrodt, Inc.

The interassay variability of the $F_{1+2}$ measurement was determined with replicate determinations of a normal plasma pool from 34 separate runs over a 1-yr period. The coefficient of variation was $8 \%$.

Preparation of normal and partially gamma decarboxylated $F_{1+2}$ for turnover studies. Human prothrombin fragment $F_{1+2}$ was purified from 2 liters of fresh frozen plasma. The procedures employed were outlined in a previous publication from our laboratory (17). Approximately $50 \%$ of the gamma carboxyglutamic acid (gla) residues of $\mathrm{F}_{1+2}$ were decarboxylated to glutamic acid by a modification of the techniques described by Poser and Price (22) and Tuhy et al. (23). $2 \mathrm{mg}$ of protein was extensively dialyzed at $4^{\circ} \mathrm{C}$ against metal-free, áspartic acid (asp)-free distilled water containing $0.01 \mathrm{M} \mathrm{HCl}$. After lyophilization, the fragment was hydrolyzed in sealed vacuum tubes for 15-20 min at $110^{\circ} \mathrm{C}$. The sample was then reconstituted in a small volume of distilled water and the $F_{1+2}$ concentration was determined from the absorbance of the solution at $280 \mathrm{~nm}$. The molar extinction coefficient for human $F_{1+2}$ was assumed to be 12.9 (12).

To measure the amount of gla in the normal and partially gamma carboxylated $\mathrm{F}_{1+2}$ samples, $\sim 100$ pmol of each protein preparation were hydrolyzed for $22 \mathrm{~h}$ in $2 \mathrm{M} \mathrm{KOH}$ in sealed tubes at $110^{\circ} \mathrm{C}$ after lyophilization (24). A known amount of ${ }^{14} \mathrm{C}$-labeled gla (New England Nuclear, Boston, MA) was "spiked" into each sample as a control to determine recoveries. The alkaline hydrolysates of the protein were reconstituted with saturated $\mathrm{KHCO}_{3}$, centrifuged for 2 min at $22^{\circ} \mathrm{C}$ at $10,000 \mathrm{~g}$, and the resulting supernatant was neutralized with $60 \%$ ( $\mathrm{vol} / \mathrm{vol}) \mathrm{HClO}_{4}$. Gla and asp content of each specimen was determined using the method of Fernlund and Stenflo (25). Samples were applied to a Resin Dionex DC-4A analytical column $(0.46 \times 10 \mathrm{~cm})$ in $0.05 \mathrm{M}$ lithium citrate, $0.09 \mathrm{M} \mathrm{LiCl}, \mathrm{pH} 2.0$, at a flow rate of $1 \mathrm{ml} / \mathrm{min}$. The gla and asp residues were eluted with $0.3 \mathrm{M} \mathrm{LiOH}$ at 4.5 and 9.5 min, respectively, and were detected fluorimetrically by treating the eluted fractions with the $O$-phthaladehyde reagent of Hughes et al. (26). Quantitation of eluted amino acids was performed using a Shimadzu C-R3A plotter-integrator. The amounts of gla and asp in each sample were derived by interpolation on linear standard curves constructed with known amounts of gla and asp (Calbiochem-Behring Corp., La Jolla, CA). The number of moles of gla per mole of protein was determined assuming that one mole of $\mathrm{F}_{1+2}$ contains 33 moles of asp (27).

${ }^{131} I-F_{1+2}$ preparation and turnover studies. Radiolabeling of normal and partially gamma decarboxylated $\mathrm{F}_{1+2}$ was accomplished by the method of Greenwood et al. (28) utilizing $15 \mu \mathrm{g}$ of protein and 0.6 $\mathrm{mCi}$ of carrier-free $\mathrm{Na}^{131} \mathrm{I}$ (New England Nuclear). Separation of free iodide from labeled protein was achieved by filtration of samples at 15 $\mathrm{ml} / \mathrm{h}$ through columns of Sephadex G-25 $(0.8 \times 26 \mathrm{~cm})$ equilibrated with $0.1 \mathrm{M}$ potassium phosphate, $\mathrm{pH} 7.0$, that contained $0.2 \%$ (wt/vol) bovine serum albumin.

Clearance studies of ${ }^{131} \mathrm{I}-\mathrm{F}_{1+2}$ were carried out in dogs. The protein was infused as a bolus into a peripheral leg vein and blood samples were drawn through a catheter placed in the jugular vein into preloaded syringes containing " $F_{1+2}$ anticoagulant." The blood samples were processed to remove cellular elements, and $0.5 \mathrm{ml}$ aliquots of plasma were counted (Gamma 8000 Counting System; Beckman Instruments, Inc., Irvine, CA). Each animal was given cold sodium iodide before injection of the labeled material to prevent uptake of radioactivity by the thyroid.

Antithrombin Concentrates. Antithrombin purified from pooled human plasma of normal donors (heat treated) was supplied by Cutter Laboratories, Inc. (Berkeley, CA). $1 \mathrm{U}$ is defined as the amount of antithrombin in $1 \mathrm{ml}$ of pooled normal human plasma.

Informed Consent. All clinical studies and informed consent procedures were approved by the Committee on Clinical Investigations, New Procedures and New Forms of Therapy of the Beth Israel Hospital.

Analysis of data. Estimation of relative immunoreactivity, computation of the slopes of the dose-response curves, as well as determinations of the various associated indices were obtained by a least-squares fit of the RIA results to a "four parameter" model as described by Rodbard $(29,30)$. Statistical analyses of data were conducted by standard techniques (31). In most instances, the means are provided with associated standard deviations.

\section{Results}

\section{Suppression of prothrombin activation in patients on oral anticoagulants}

We have measured the levels of prothrombin activation fragment $F_{1+2}$ in 23 patients (median age $49 \mathrm{yr}$ ) maintained on chronic warfarin therapy for the prophylaxis of venous thrombosis or cardiac emboli secondary to either atrial fibrillation, ventricular aneurysm, mitral, or aortic valve replacement, etc. These individuals were all stably anticoagulated for a minimum of 3 mo before evaluation with PT ratios that ranged from 1.39 to 2.79 (mean PT ratio $=1.74 \pm 0.32$ ). None of the subjects was found to have a deficiency of antithrombin, protein $\mathrm{C}$, or protein S (data not shown) nor did any exhibit clinical or laboratory evidence of hepatic or renal dysfunction. The mean plasma level of $F_{i+2}$ was significantly decreased in this population as compared with a control group of healthy age-matched individuals (32) who possessed normal levels of antithrombin, protein $C$, and protein $S(0.231 \pm 0.24 \mathrm{nM}$ vs. $1.68 \pm 0.81 \mathrm{nM}, P<0.0001$ ). The relationship between $\mathrm{F}_{1+2}$ concentration and $\mathrm{PT}$ ratio in this anticoagulated population is shown in Fig. 1. 


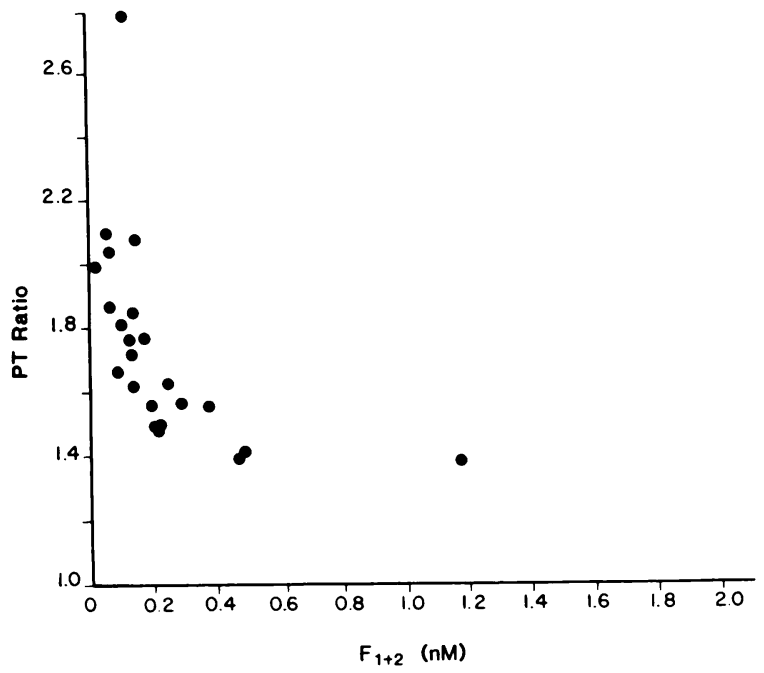

Figure 1. Relationship between $\mathrm{F}_{1+2}$ level and PT ratio in 23 patients maintained on chronic warfarin therapy for the prophylaxis of venous thrombosis or systemic emboli secondary to various types of cardiac disease. The mean plasma $F_{1+2}$ concentration and mean PT ratio in this population were $0.231 \pm 0.24 \mathrm{nM}$ and $1.74 \pm 0.32$, respectively.

Warfarin is able to interfere with the normal carboxylation mechanism of the liver resulting in the production of vitamin $\mathrm{K}$-dependent proteins with less than their full complement of gla residues. Gla residues enable these proteins to bind to phospholipid surfaces in the presence of calcium ions. This results in a dramatic acceleration in the rate of conversion of vitamin $\mathrm{K}$-dependent coagulation zymogens to their corresponding serine proteases. Normal prothrombin contains $10 \mathrm{~mol}$ of gla per mole of protein that are localized to the $\mathrm{NH}_{2}$-terminal region of the $F_{1}$ domain of the molecule. Friedman et al. (33) have observed that prothrombin isolated from the plasma of patients ingesting oral anticoagulants on a chronic basis consists of a wide spectrum of abnormal molecules that contain varying quantities of gla per mole of zymogen. These investigators determined that only $50 \%$ of the protein was able to bind to phospholipid micelles and that these species contained $\sim 6.5 \mathrm{~mol}$ of gla per mole of protein. Esnouf and Prowse have also found that the warfarin-induced zymogen must possess at least 7 gla residues per mole of protein to exhibit coagulant activity (34).

Based upon the above data, it is possible that partially gamma carboxylated forms of prothrombin in the plasma of individuals receiving warfarin might be activated in vivo to thrombin with release of abnormal $F_{1+2}$ molecules with decreased numbers of gla residues. Under these conditions, the validity of the $F_{1+2}$ assay as an index for the activation of prothrombin in patients on oral anticoagulants would be dependent on the elimination of two potential sources of error. First, the immunoreactivity of the partially gamma carboxylated $F_{1+2}$ fragment in this population must be similar to that in normal subjects. Second, the metabolic behavior of partially gamma carboxylated $F_{1+2}$ generated in individuals on warfarin must not be altered as compared with the native activation polypeptide.

These two issues were addressed by preparing two batches of $F_{1+2}$ with $<70 \%$ of the full complement of gla residues by thermal decarboxylation (see Methods). This procedure has previously been employed to produce gamma decarboxylated forms of prothrombin and $F_{1}$ without inducing significant alterations in secondary structure as judged by spectroscopic examination (23). Our studies revealed that native $F_{1+2}$ had 9.3 mol of gla per mole of fragment that is concordant with the value of 10 previously obtained by mass spectrometry $(35,36)$. The two partially decarboxylated preparations exhibited 5.9 and 6.3 gla residues per mole of protein, respectively (Table I).

The first potential source of error was examined by determining the relative immunoreactivity of the fully and partially gamma carboxylated forms of $F_{1+2}$. This property was defined by contrasting the molar concentrations of the two $F_{1+2}$ species required to displace $50 \%$ of the immunoprecipitable ${ }^{125} \mathrm{I}-\mathrm{F}_{1+2}$ counts from our specific antibody. The mean slopes and midpoints of the logit-log dose-response curves for the two preparations of partially carboxylated $F_{1+2}$ were similar to those obtained for the native activation fragment (Table I). Thus, these data indicate that partially carboxylated and normal forms of $F_{1+2}$ have virtually identical immunochemical characteristics. It should also be noted that the immunogen utilized to raise the $F_{1+2}$ antisera was $F_{2}$, which does not contain any gla residues, and that the immunoreactive site defined by our antibody population is most probably located within the COOH-terminal region of the $F_{2}$ domain of the $F_{1+2}$ fragment (12).

The second potential source of error was investigated by ascertaining the metabolic behavior of fully and partially carboxylated preparations of $F_{1+2}$ in dogs. We have previously shown that the clearance rate of native ${ }^{131} I-F_{1+2}$ in dogs is similar to that in man (17). To this end, the fully and partially gamma carboxylated forms of $F_{1+2}$ were radiolabeled with ${ }^{131} \mathrm{I}$, and turnover studies with the various radiolabeled species were undertaken. No substantial differences were noted in the metabolism of fully and partially gamma carboxylated forms of $\mathrm{F}_{1+2}$ (Table I). This impression was confirmed by fitting the data obtained during the $1 \mathrm{st} 6 \mathrm{~h}$ to a two-exponential curve (37) that allowed us to compute several metabolic parameters (38).

Table I. Characterization of Normal and Partially Gamma Carboxylated $F_{1+2}$

\begin{tabular}{llll}
\hline & & \multicolumn{2}{l}{$\begin{array}{l}\text { Partially gamma } \\
\text { carboxylated } \mathrm{F}_{1+2}\end{array}$} \\
\cline { 3 - 4 } & $\begin{array}{l}\text { Normal } \\
\mathrm{F}_{1+2}\end{array}$ & $\begin{array}{l}\text { Preparation } \\
1\end{array}$ & $\begin{array}{l}\text { Preparation } \\
2\end{array}$ \\
\hline $\begin{array}{l}\text { Moles of gla per mole of } \\
\text { protein }\end{array}$ & 9.3 & 5.9 & 6.3 \\
$\begin{array}{c}\text { Component immunoreactivity } \\
\text { compared with normal } \mathrm{F}_{1+2}\end{array}$ & 1.0 & 1.13 & 1.18 \\
$\begin{array}{c}\text { on a molar basis } \\
\begin{array}{c}\text { Average slope of dose- } \\
\text { response curve }\end{array}\end{array}$ & 0.99 & 1.01 & 1.09 \\
$\begin{array}{c}\text { Fractional breakdown rate }\left(K_{B}\right. \\
\left.\left[h^{-1}\right]\right)^{*}\end{array}$ & 0.24 & 0.21 & 0.25 \\
\hline
\end{tabular}

* Plasma radioactivity measurements obtained from turnover studies were plotted against time; ${ }^{131} \mathrm{I}-\mathrm{F}_{1+2}$ plasma radioactivity is described by a two-exponential curve, $C_{1} \mathrm{e}^{-r_{1} t}+C_{2} \mathrm{e}^{-r_{2} t}(37)$. The fractional breakdown rate, $K_{B}\left(\mathrm{~h}^{-1}\right)$, was calculated from $\left.C_{1} / r_{1}+C_{2} / r_{2}\right)^{-1}(38)$. 
Studies of patients with thrombotic diatheses and elevated plasma $F_{1+2}$ levels before the initiation of anticoagulant therapy

Based upon the above data, we conclude that the decrease in $F_{1+2}$ levels observed in patients on a stable program of oral anticoagulation accurately reflects the diminished activation of prothrombin by Factor Xa. We next proceeded to study the alterations in hemostatic system activation as measured by the RIAs for $F_{1+2}, F P A$, and PCP during the initiation of warfarin therapy in individuals with a history of recurrent venous thrombosis. We have also examined the changes in the above parameters relative to the intensity of oral anticoagulation in this population as well as the effects of this medication on $F_{1+2}$ levels in subjects with hereditary deficiencies of antithrombin and protein $C$. The individuals participating in these investigations were selected from a cohort of patients referred to our laboratory for hemostatic evaluation. Patients enrolled in these research protocols had been free of thrombotic complications for at least 3 mo before study. In subjects studied before the institution of antithrombotic therapy, routine coagulation studies, including PT and partial thromboplastin time, were within normal limits. None of the subjects exhibited clinical or laboratory evidence of hepatic or renal dysfunction.

Hemostatic system activation during the initiation of oral anticoagulants. We have carried out detailed investigations of the sequential changes in the levels of $F_{1+2}$, FPA, and PCP in two patients with a prior history of recurrent venous thromboembolism during the initiation of oral anticoagulation (Fig. 2).

Subject 1 was a 59 -yr-old male who was not congenitally deficient in antithrombin, protein $\mathrm{C}$, or protein $\mathrm{S}$ (Fig. $2 A$ ). The baseline plasma measurements of $F_{1+2}$, FPA, and PCP in this individual were all substantially elevated at $3.47 \mathrm{nM}, 2.11$ $\mathrm{nM}$, and $3.12 \mathrm{pM}$, respectively. Treatment was initiated with $7.5 \mathrm{mg}$ of sodium warfarin daily, and the medication dose was adjusted to attain a PT ratio of 1.8 to 2.0. This intensity of anticoagulation was achieved in $5 \mathrm{~d}$. The $\mathrm{F}_{1+2}$ concentration was observed to rise to $4.68 \mathrm{nM}$ after $1 \mathrm{~d}$ of therapy and steadily fell in the ensuing days reaching a level of $1.70 \mathrm{nM}$ on day 5 that was within the normal range. Maximal suppression of Factor Xa enzymatic activity was observed on day 17. Our results indicate that the plasma FPA concentration also increased on day 1, whereas the PCP determination did not change appreciably. The levels of FPA and PCP then proceeded to fall to 0.90 and $1.53 \mathrm{nM}$, respectively, by day 5 . The FPA and PCP determinations remained stably suppressed at these concentrations during the remainder of the study. The immunologic level of protein C zymogen declined from $145 \%$ of normal to $121 \%$ on day 1 and reached a stable level of $66 \%$ by day 4; the functional level of protein $\mathrm{C}$ dropped sharply from a baseline value of $140 \%$ of normal to $90 \%$ on day 1 . Plasma prothrombin measurements as determined by RIA showed essentially no change during the 1 st $24 \mathrm{~h}$ of therapy and then gradually decreased to a level of $70 \%$ of normal over a 2-wk period.

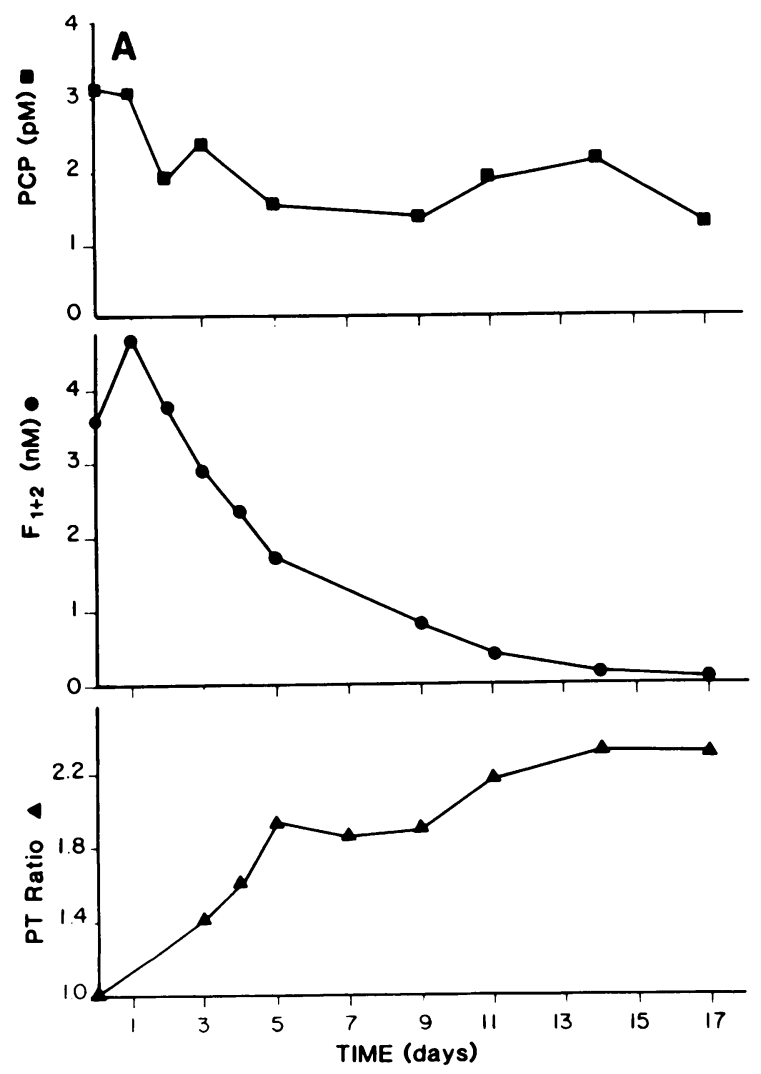

Figure 2. Sequential changes in the levels of $\mathrm{PCP}, \mathrm{F}_{1+2}$, and PT ratio in subjects $1(A)$ and $2(B)$ during the initiation of oral anticoagulation without a loading dose. Both individuals had previously sustained multiple episodes of venous thromboembolism and had ele-

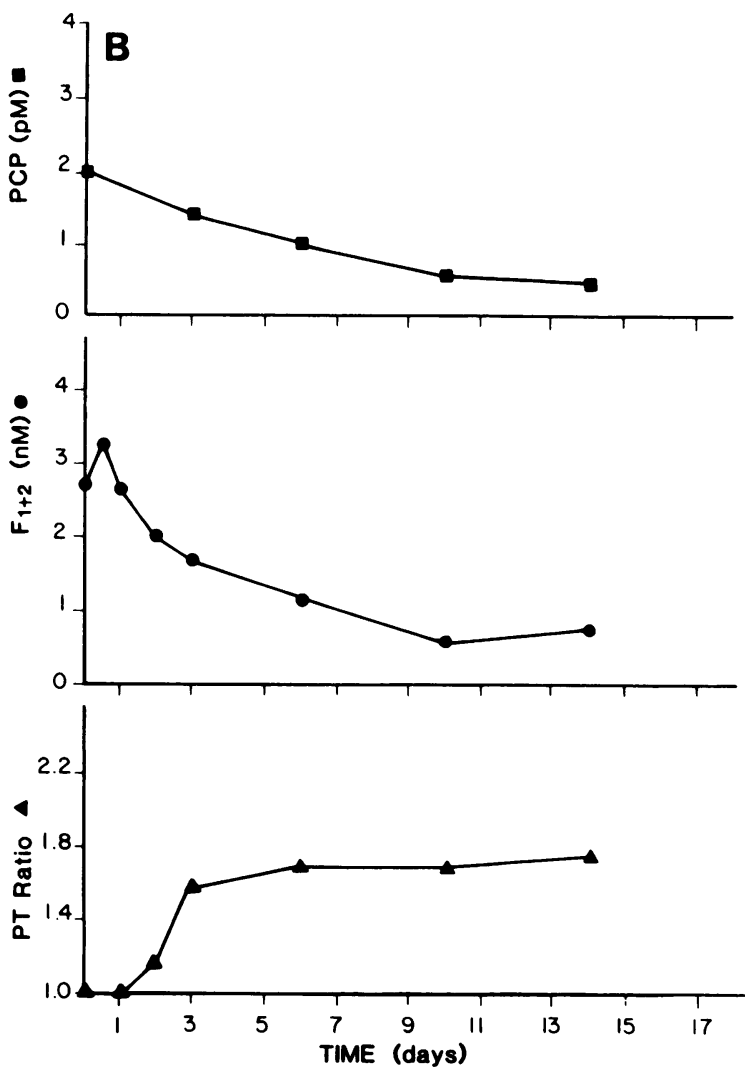

vated plasma $F_{1+2}$ levels before the initiation of anticoagulant therapy. Subject 1 did not have an identifiable inherited thrombotic disorder, and subject 2 had congenital antithrombin deficiency. 
Subject 2 was a 33-yr-old female with congenital antithrombin deficiency (Fig. 2 B). The baseline plasma measurements of $F_{1+2}$, FPA, and PCP in this woman were 2.67 $\mathrm{nM}, 0.92 \mathrm{nM}$, and $2.03 \mathrm{pM}$, respectively. Treatment was initiated with $10 \mathrm{mg}$ of sodium warfarin for $4 \mathrm{~d}$ followed by a maintenance dose of $7.5 \mathrm{mg}$ daily. A PT ratio of 1.7 was achieved by day 6 . The plasma $F_{1+2}$ concentration in this patient also increased to $3.19 \mathrm{nM}$ within the first day of therapy and gradually fell to a level of 1.13 by day 6 . A value of 0.56 $\mathrm{nM}$ was attained by day 10 . The PCP determinations decreased in a manner similar to those observed in patient 1 , whereas the plasma FPA levels remained relatively stable throughout the duration of the study. The immunologic level of protein C zymogen declined from 106\% of normal to $85 \%$ on day 1 and reached a stable concentration of $45 \%$ by day 4 ; the functional level of protein $\mathrm{C}$ dropped from a baseline level of $110 \%$ of normal to $60 \%$ on day 1 . Plasma prothrombin measurements as determined by RIA were unchanged at $24 \mathrm{~h}$ and decreased to a level of $60 \%$ of normal over a 2-wk period, whereas the functional antithrombin determinations did not change appreciably.

The effect of low dose warfarin on the hemostatic mechanism. We next conducted sequential studies of five patients on warfarin regimens of varying intensity (Table II). The extent of hemostatic system activation as measured by the $F_{1+2}$, FPA, and PCP assays was evaluated at weekly intervals starting $3 \mathrm{wk}$ after the onset of treatment. The dose of warfarin was adjusted at monthly intervals to achieve a stable intensity of oral anticoagulation. The targeted PT ratios were 1.4 to 1.8 (level I) and 1.0 to 1.3 (level II). To demonstrate that the levels of these in vivo markers of coagulation system activity repre- sented stable parameters characteristic of a particular individual at a given point of time, we obtained blood samples on each subject on multiple occasions at each level of anticoagulant intensity at intervals ranging from weeks to months. In four of the five patients, we were able to discontinue anticoagulation at the completion of our investigations and the levels of $F_{1+2}, F P A$, and PCP returned to their pretreatment values (data not shown).

Subjects 1 and 2 were the same individuals who had participated in our investigations of alterations in coagulation system activity during the initiation of oral anticoagulation and were studied at two intensity levels. A daily warfarin dose of 5 $\mathrm{mg} / \mathrm{d}$ resulted in the maintenance of a PT ratio of 1.41 to 1.68 (level I) in subject 1 . This level of therapy caused a suppression of $F_{1+2}$ levels from a baseline value of 3.47 to $0.37 \mathrm{nM}$. The FPA and PCP values also decreased from $2.11 \mathrm{nM}$ and 3.12 $\mathrm{pM}$ to $1.06 \mathrm{nM}$ and $1.17 \mathrm{pM}$, respectively. The daily dose of medication was then reduced to $3 \mathrm{mg} / \mathrm{d}$, which resulted in a PT ratio that ranged between 0.90 and 1.06 (level II). The measurements of $F_{1+2}, F P A$, and PCP were $1.48 \mathrm{nM}, 1.25 \mathrm{nM}$, and $1.20 \mathrm{pM}$, respectively. Only the $\mathrm{F}_{1+2}$ measurements were significantly different at the two intensity levels of oral anticoagulation. In subject 2 , a daily warfarin dose of $7 \mathrm{mg} / \mathrm{d}$ resulted in the maintenance of a PT ratio of 1.54 to 1.73 (level I). This resulted in the suppression of $F_{1+2}$ levels from a baseline value of 2.67 to $0.88 \mathrm{nM}$. The PCP values also decreased substantially from 2.03 to $0.52 \mathrm{pM}$, whereas FPA measurements did not change significantly. The daily dose of drug was then reduced to $4 \mathrm{mg} / \mathrm{d}$, which resulted in a PT ratio that ranged between 1.00 and 1.20 (level II). The mean $F_{1+2}$ level was 1.45 $\mathrm{nM}$, which was within the normal range. The concentrations

Table II. Levels of $F_{1+2}, P C P$, and FPA at Varying Intensity Levels of Oral Anticoagulation

\begin{tabular}{|c|c|c|c|c|c|}
\hline & \multicolumn{5}{|c|}{ Subject number } \\
\hline & 1 & 2 & 3 & 4 & 5 \\
\hline \multicolumn{6}{|l|}{ Baseline } \\
\hline Number of determinations & 3 & 2 & 2 & 1 & 2 \\
\hline PT Ratio* & 0.94 & 0.97 & 0.98 & 1.0 & 0.95 \\
\hline $\mathrm{F}_{1+2}(n M)$ & $3.47 \pm 0.30$ & 2.67 & 3.74 & 2.96 & 3.28 \\
\hline FPA $(n M)$ & $2.11 \pm 0.17$ & 0.92 & 2.00 & 2.33 & 1.78 \\
\hline $\mathrm{PCP}(p M)$ & $3.12 \pm 0.28$ & 2.03 & 1.72 & 2.56 & 1.73 \\
\hline \multicolumn{6}{|l|}{ Level I } \\
\hline Warfarin dose $(m g / d)$ & 5 & 7 & & & \\
\hline Number of determinations & 5 & 4 & & & \\
\hline PT Ratio (range)* & $1.41-1.68$ & $1.54-1.73$ & & & \\
\hline $\mathrm{F}_{1+2}(n M)$ & $0.37 \pm 0.04$ & $0.88 \pm 0.22$ & & & \\
\hline FPA $(n M)$ & $1.06 \pm 0.25$ & $0.77 \pm 0.09$ & & & \\
\hline $\mathrm{PCP}(p M)$ & $1.17 \pm 0.33$ & $0.52 \pm 0.16$ & & & \\
\hline \multicolumn{6}{|l|}{ Level II } \\
\hline Warfarin dose $(m g / d)$ & 3 & 4 & 1 & 10 & 2 \\
\hline Number of determinations & 5 & 5 & 2 & 2 & 4 \\
\hline PT Ratio (range)* & $0.90-1.06$ & $1.00-1.20$ & 0.95 & $1.00-1.16$ & $1.07-1.29$ \\
\hline $\mathrm{F}_{1+2}(n M)$ & $1.48 \pm 0.10$ & $1.45 \pm 0.21$ & 1.84 & 1.00 & $1.29 \pm 0.21$ \\
\hline FPA $(n M)$ & $1.25 \pm 0.45$ & $1.08 \pm 0.25$ & 1.40 & 0.84 & $1.89 \pm 0.37$ \\
\hline $\mathrm{PCP}(p M)$ & $1.20 \pm 0.53$ & $0.63 \pm 0.16$ & 1.32 & 0.58 & $0.31 \pm 0.04$ \\
\hline
\end{tabular}

* PT ratio = PT of patient/PT of normal plasma pool. The targeted PT ratios for anticoagulant intensity levels I and II were 1.4-1.8 and 1.0-1.3, respectively. The mean plasma levels of $F_{1+2}$, FPA, and PCP in a control group of healthy age-matched individuals were $1.68 \pm 0.81$ $\mathrm{nM}, 0.99 \pm 0.83 \mathrm{nM}$, and $1.97 \pm 0.70 \mathrm{pM}$, respectively (32). 
of FPA and PCP were $1.08 \mathrm{nM}$ and $0.63 \mathrm{pM}$, respectively, which were not significantly different from the values obtained during the more intense anticoagulation regimen $(P>0.05)$.

The above results demonstrate that the plasma $F_{1+2}$ level can be suppressed into the normal range on a very low intensity warfarin regimen in which the PT ratio is essentially indistinguishable from normal. We have also carried out sequential studies of this very low intensity program of oral anticoagulation (level II) in three additional individuals (Table II). Subject 3 is a 45-yr-old male with a history of portal vein thrombosis in association with hereditary protein $\mathrm{C}$ deficiency. The immunologic level of the zymogen in this patient was $41 \%$ of normal before anticoagulation. Subject 4 is a 40 -yr-old male with a history of venous thrombosis starting at age $18 \mathrm{yr}$ who was found to be congenitally deficient in protein $S$ with a total antigen level of $50 \%$. Subject 5 is a 57 -yr-old female with an elevated $F_{1+2}$ value off warfarin therapy who did not have an identifiable biochemical abnormality to explain her thrombotic tendency. The plasma $F_{1+2}$ level in each patient was substantially elevated as compared with age-matched normal controls before the institution of oral anticoagulants (Table II). All three individuals demonstrated suppression of prothrombin activation as measured by the $F_{1+2}$ RIA on doses of sodium warfarin ranging from 1 to $2.5 \mathrm{mg} / \mathrm{d}$. In all instances, the PT ratio was $<1.20$. The PCP concentrations were also substantially reduced from their baseline values in the three patients, whereas the FPA levels were reduced in only subjects 3 and 4 . In summary, the mean levels of $F_{1+2}$ and PCP in the five patients decreased substantially from their baseline values on the very low intensity warfarin regimen (mean PT ratio $=1.10), 1.41 \pm 0.31$ vs. $3.22 \pm 0.42 \mathrm{nM}, P<0.0005$, and $0.808 \pm 0.43$ vs. $2.23 \pm 0.60 \mathrm{pM}, P<0.01$, respectively. The values of FPA were not significantly different, $1.29 \pm 0.39$ vs. $1.83 \pm 0.55 \mathrm{nM}, P>0.05$.

The effect of warfarin on the hemostatic mechanism in patients with hereditary deficiencies of antithrombin and protein $C$. We have previously reported that significant elevations in Factor Xa activity but not thrombin activity regularly occur in the blood of many asymptomatic nonanticoagulated individuals with hereditary deficiencies of antithrombin (17) or protein $\mathrm{C}^{2}$ In pursuing these investigations, blood samples were also obtained for measurements of $F_{1+2}$ from relatives with these disorders who had a severe thrombotic diathesis and were chronically maintained on oral anticoagulants.

A total of 12 antithrombin-deficient subjects derived from seven families were studied (Fig. $3 A$ ). The mean plasma antithrombin concentration as determined by heparin cofactor assay was $47.2 \% \pm 13.1$ of normal, and the median age of this cohort on the date of evaluation was $40 \mathrm{yr}$. These individuals had a mean PT ratio of $1.85 \pm 0.41$ (range from 1.31 to 2.44). The mean plasma $F_{1+2}$ level was significantly increased in this population as compared with the group of 23 nonantithrombin-deficient patients shown in Fig. 1 who had an equivalent intensity level of oral anticoagulation, $0.714 \pm 0.26 \mathrm{nM}$ vs. $0.231 \pm 0.24 \mathrm{nM}, P<0.01$. This relative resistance to the suppression of Factor $\mathrm{Xa}$ enzymatic activity by warfarin as measured by the PT was also evident in subject 2 (Table II). However, we noted that the antithrombin-deficient subjects constituted an extremely heterogeneous population in terms of the relationship between the level of $F_{1+2}$ and the PT ratio. As only three of these 12 individuals have been investigated in the absence of oral anticoagulant therapy, we are unable to draw any conclusions regarding the role that warfarin-induced increments in the plasma antithrombin concentration might play in reducing the extent of prothrombin activation in these subjects.

We have also shown that the infusion of antithrombin concentrate into three stably anticoagulated patients with a deficiency of this protease inhibitor leads to further suppression of plasma $F_{1+2}$ levels (Table III). After obtaining baseline blood studies, each subject received an infusion of the purified protein via a peripheral vein at a dosage of $25-50 \mathrm{U} / \mathrm{kg}$. Blood samples were obtained by separate venipuncture at various time points after the medication was administered. Our results indicate that the mean plasma antithrombin concentration increased from a mean basal value of $48 \%$ of normal to a mean level of $120 \% 6 \mathrm{~h}$ after the completion of the infusion. The mean plasma $F_{1+2}$ measurement decreased from $0.697 \pm 0.29$ $\mathrm{nM}$ to $0.103 \pm 0.06 \mathrm{nM}$. The above results allow us to conclude that the effect of warfarin on hemostatic system activation is modulated by the endogenous heparan sulfate-antithrombin mechanism.
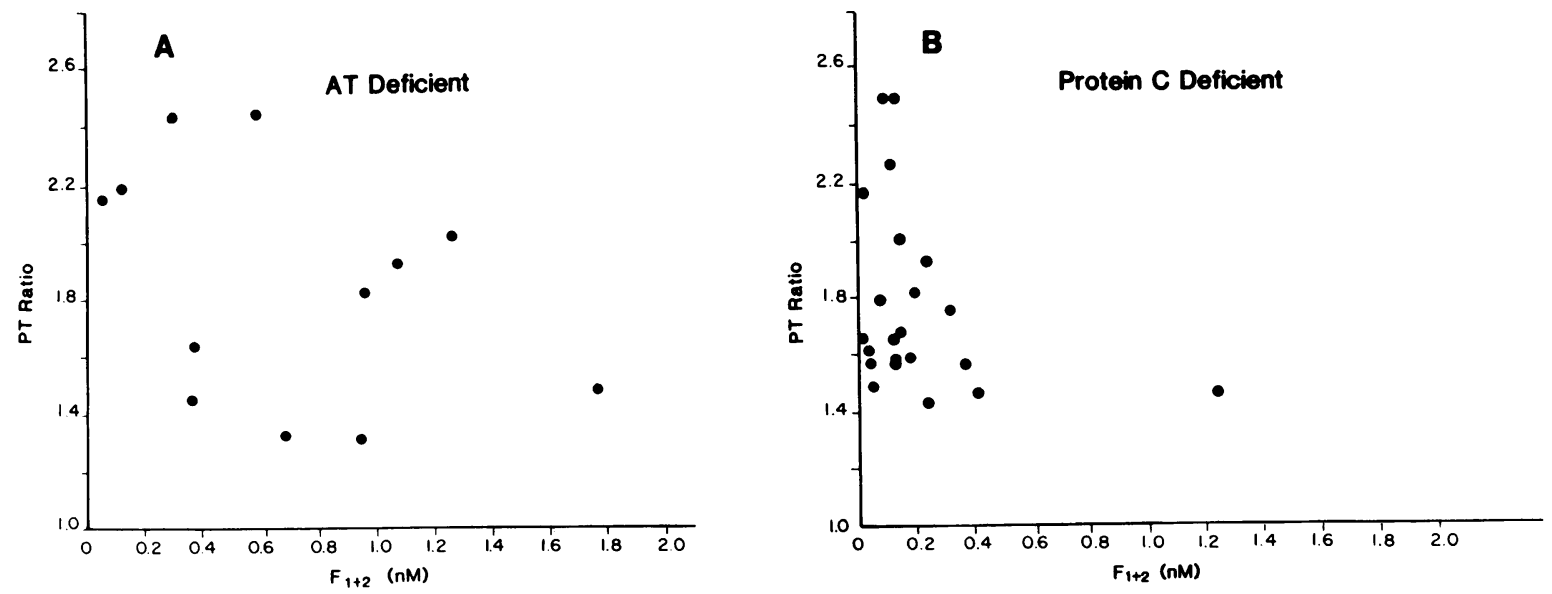

Figure 3. Relationship between $\mathrm{F}_{1+2}$ level and PT ratio in chronically anticoagulated patients with inherited deficiencies of antithrombin $(A)$ and protein $C(B)$. The mean plasma $F_{1+2}$ concentration and mean PT ratio were $0.714 \pm 0.26 \mathrm{nM}$ and $1.85 \pm 0.41 \mathrm{nM}$ in the antithrombin-deficient individuals, and $0.205 \pm 0.25 \mathrm{nM}$ and $1.78 \pm 0.32$ in the protein $C$-deficient subjects, respectively. 
Table III. Response of $F_{1+2}$ Levels in Antithrombin-Deficient Patients on Warfarin to Antithrombin Concentrate Infusions

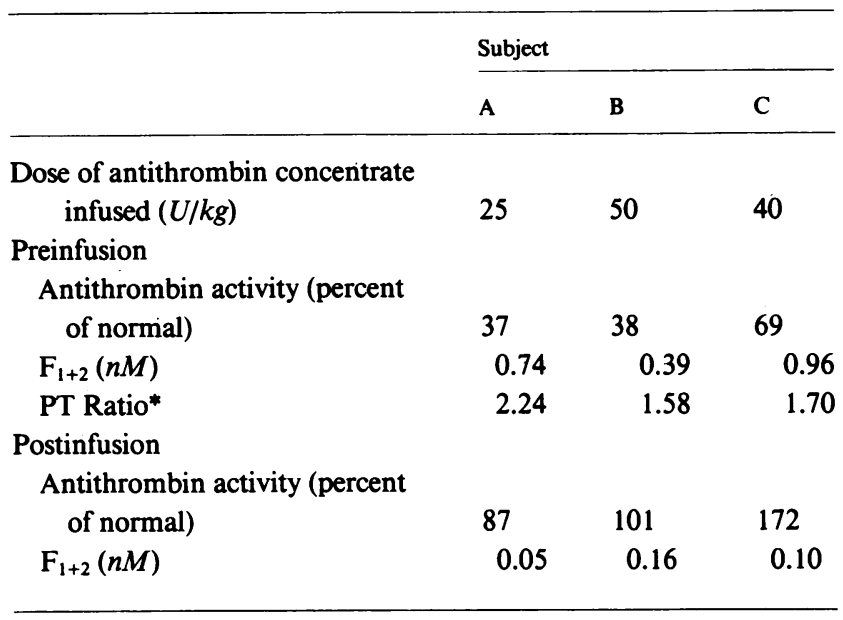

* PT ratio = PT of patient/PT of normal plasma pool.

The observed effect of warfarin in antithrombin-deficient patients is in sharp contrast to the action of the anticoagulant in 22 individuals from 12 kindreds with heterozygous protein $\mathrm{C}$ deficiency (Fig. $3 \mathrm{~B}$ ). We have reported the individual $\mathrm{F}_{1+2}$ values in 13 of these individuals in another communication. ${ }^{2}$ The mean immunologic plasma protein $\mathrm{C}$ concentration of this cohort was $26.7 \% \pm 5.6$ of normal, and their median age was $40 \mathrm{yr}$. The mean plasma $F_{1+2}$ level and mean PT ratio in this population were similar to those which were noted in the 23 patients without a biochemical deficiency of antithrombin, protein $C$, or protein $S(0.205 \pm 0.25 \mathrm{nM}$ and $1.78 \pm 0.32$ vs. $0.231 \pm 0.24 \mathrm{nM}$ and $1.74 \pm 0.32$, respectively, $P>0.05$ ).

\section{Discussion}

The 4-hydroxycoumarin drugs are widely used oral anticoagulants that function by lowering the plasma activity of the vitamin K-dependent blood coagulation proteins (i.e., prothrombin, Factors VII, Factor IX, Factor X, protein C, and protein S). Numerous clinical trials have shown that these drugs are effective in the treatment of venous thromboembolism $(39-41)$. Also, this anticoagulant is of value in the prophylaxis of venous thrombosis in high risk patients $(42,43)$ and systemic embolism in patients with various types of cardiac disease (44). Warfarin therapy is usually monitored by the onestage PT, which provides an estimate of the functional activity of Factor VII, Factor X, and prothrombin. This assay utilizes various concentrations of animal or human tissue thromboplastin to activate the extrinsic coagulation cascade and thereby convert prothrombin to thrombin under arbitrary in vitro conditions. Despite improvements in the monitoring of therapy with this test in recent years, the optimum level of anticoagulant intensity, i.e., that level which provides protection against thrombosis with a minimal risk of bleeding, has not yet been established.

In this communication, we have employed a series of immunoassays that quantitate the in vivo activities of various steps of the hemostatic mechanism to study patients receiving sodium warfarin. Our results demonstrate that prothrombin activation as measured by the $F_{1+2}$ assay is markedly suppressed in this population, and that the observed reduction in the plasma levels of this component is not due to decreased immunoreactivity or rapid clearance of partially gamma carboxylated forms of the fragment. Thus, the $F_{1+2}$ assay should serve as an accurate marker of Factor Xa activity upon prothrombin in the blood of individuals ingesting oral anticoagulants. Utilizing RIAs for $\mathrm{F}_{1+2}$, FPA, and PCP, we performed sequential studies to investigate hemostatic system activation during initiation of warfarin therapy and at various levels of anticoagulant intensity in patients with a history of recurrent venous thromboembolism and elevated plasma $F_{1+2}$ levels. We have also compared the effect of this drug on the measurements of $F_{1+2}$ in subjects with hereditary deficiencies of antithrombin and protein $\mathrm{C}$ with the action of the medication on the concentration of this marker in anticoagulated patients without an inherited thrombotic disorder.

Hemostatic system activation during the initiation of oral anticoagulants. The initiation of warfarin therapy led to a paradoxical increase in plasma $F_{1+2}$ levels witin the 1 st $24 \mathrm{~h}$ in two subjects who were not protein $C$ deficient. This observation provides direct biochemical data to support the hypothesized mechanism of warfarin-induced skin necrosis. This rare clinical syndrome usually occurs during the first several days of administration of oral anticoagulants and results in the appearance of skin lesions due to diffuse thrombosis of the venules with interstitial bleeding. It has been postulated that the rapid suppression of the anticoagulant activity of protein $\mathrm{C}$ relative to the decrease in the levels of Factor VII as well as other vitamin $\mathrm{K}$-dependent factors leads to the emergence of a transient hypercoagulable state.

D'Angelo et al. have previously examined this issue utilizing coagulant assays for protein C, Factor VII, and Factor X (45). They found that the mean protein $C$ antigen and anticoagulant activity levels dropped to $\sim 80$ and $50 \%$ of baseline values, respectively, $1 \mathrm{~d}$ after starting warfarin therapy without a loading dose. These values were depressed an additional $25 \%$ when a loading-dose regimen (i.e., $20-30 \mathrm{mg}$ for the 1 st $2 \mathrm{~d}$ ) was administered (45). Given the above data, it was estimated that the $t_{1 / 2}$ of fully carboxylated protein $\mathrm{C}$ within the circulation is $\sim 16 \mathrm{~h}$. The Factor VII coagulant activity determinations followed a pattern virtually identical to the protein $\mathrm{C}$ anticoagulant activity measurements that is concordant with the similar $t_{1 / 2}$ of these two fully carboxylated coagulation proteins. Factor $\mathrm{X}$ levels declined at a slower rate consistent with a $t_{1 / 2}$ of $\sim 48 \mathrm{~h}$, which is similar to that which has been observed for protein $\mathrm{S}$, another vitamin $\mathrm{K}$-dependent factor (46). Based upon the above information, it is difficult to determine the net effect of drug-induced alterations of protein $\mathrm{C}$ and Factor VII on the in vivo generation of thrombin during the initiation of anticoagulant therapy.

Our studies show an increased extent of prothrombin-tothrombin conversion during the early phase of warfarin therapy. Thus, it would appear that the early in vivo action of the drug on protein $\mathrm{C}$ is more profound than its effect on Factor VII. We have also noted that the concentrations of protein $\mathrm{C}$ antigen and protein $C$ anticoagulant activity decline at $24 \mathrm{~h}$ to an extent similar to that observed by D'Angelo et al. (45), whereas the levels of PCP do not change appreciably during this time interval. This latter measurement provides an index of the in vivo activation of protein $\mathrm{C}$ by thrombin bound to thrombomodulin on the vascular endothelium. Therefore, the elevations in plasma $F_{1+2}$ levels that occur during the first day of warfarin therapy are best correlated with the decrease in 
protein $\mathrm{C}$ anticoagulant activity rather than a reduced extent of zymogen activation. This phenomenon presumably arises from the diminished ability of partially carboxylated forms of activated protein $\mathrm{C}$ to interact with membrane sites on which Factor $\mathrm{Va}$ is bound.

Despite having studied a small number of subjects initiating warfarin therapy, we surmise that an early rise in the Factor Xa dependent cleavage of prothrombin may occur in many individuals with elevated plasma $F_{1+2}$ values who start this medication and that this effect might be augmented when loading-dose schedules are utilized. The reduced extent of protein $\mathrm{C}$ activation that has been observed by us in many nonanticoagulated patients with heterozygous protein $\mathrm{C}$ deficiency $^{2}$ potentially renders these subjects particularly susceptible to an augmented early rise in plasma $F_{1+2}$ that could lead to warfarin-induced skin necrosis. However clinical studies suggest that only $\sim 30 \%$ of these cases are associated with hereditary protein $C$ deficiency (47). Indeed, any lesion in the protein $\mathrm{C}$ anticoagulant pathway might also predispose affected individuals to the above phenomenon. In this regard, it is of interest to note that this syndrome has recently been described in a patient with heterozygous protein S deficiency (48).

After the initial rise on day 1 , the $\mathrm{F}_{1+2}$ and PCP concentrations gradually fell and reached the normal range by $\sim$ day 5 of warfarin therapy. At this point in time, it has been observed that the activity levels of Factors IX and X and prothrombin are substantially reduced (49). Maximal suppression of prothrombin activation was observed 2 wk after the initiation of oral anticoagulation.

The effect of low dose warfarin on the hemostatic mechanism. The substantial suppressive effect of standard warfarin schedules on prothrombin activation in patients without an inherited thrombotic diathesis suggested that a less intense anticoagulation regimen might lead to a significant reduction of elevated plasma $F_{1+2}$ levels into the normal range rather than to subnormal concentrations. We therefore studied the response of the hemostatic mechanism to a very low intensity anticoagulation program (PT ratio $<1.3$ ) in five patients with a prior history of thrombotic disease. All of these individuals had elevated plasma $F_{1+2}$ levels before the institution of warfarin therapy. The administration of low doses of the drug led to a decrease in the concentration of this marker into the normal range at a mean PT ratio that was essentialy indistinguishable from untreated subjects.

We have previously shown that patients on oral anticoagulants with PT ratios $>1.5$ exhibit a reduction of plasma PCP levels (14). This effect presumably arises due to diminished thrombin generation with resultant suppression of protein $C$ activation. Furthermore, a decrease in the plasma concentration of protein $\mathrm{C}$ and/or its gla content may also contribute to this phenomenon. PCP values were consistently suppressed from their baseline values on the very low intensity warfarin regimen to an extent similar to that observed at more intense levels of anticoagulation. The mean level of FPA did not show a significant decrease in the five patients treated with the very low intensity program. Therefore, our data suggests that $F_{1+2}$ is a more sensitive marker than either PCP or FPA in differentiating varying intensities of oral anticoagulant therapy.

In the United States, the generally accepted therapeutic range for the PT ratio in patients receiving warfarin has been considered to be $\sim 1.5-2.0$ utilizing rabbit brain thromboplastin. Hull et al. have conducted clinical trials to determine the optimal therapeutic range for the PT in patients treated with oral anticoagulants for proximal vein thrombosis (39-41). These investigators have demonstrated that a less intense warfarin regimen equivalent to a PT ratio of $1.2-1.3$ is as effective as standard anticoagulant therapy in preventing recurrent venous thromboembolism and is associated with a reduced risk of hemorrhagic complications (41). Other groups have shown that low intensity warfarin schedules resulting in PT ratios between 1.3 and 1.5 are effective for the prophylaxis of venous thrombosis in high risk surgical patients $(42,43)$. Our documentation of the suppression of elevated plasma $F_{1+2}$ levels in individuals with hypercoagulable syndromes into the normal range with a low intensity of anticoagulant therapy is consistent with the above clinical observations.

It must be emphasized that our biochemical observations cannot presently be interpreted as demonstrating a therapeutic effect of very low intensity warfarin schedules. The extent of prothrombin activation at which antithrombotic protection is afforded will need to be determined by properly designed prospective studies with objective clinical endpoints for thrombotic events.

The effect of warfarin on the hemostatic mechanism of patients with hereditary deficiencies of antithrombin and protein $C$. The presence of $F_{1+2}$, PCP, and FPA within the blood under normal conditions indicates that hemostatic enzymes are continuously generated within the vascular system. We have previously demonstrated that many nonanticoagulated patients with hereditary deficiencies of antithrombin and protein $\mathrm{C}$ have elevated levels of Factor $\mathrm{Xa}$ activity as measured by the $F_{1+2}$ assay (17). ${ }^{2}$ The hemostatic system hyperactivity in the antithrombin-deficient individuals could be specifically corrected by raising the plasma levels of the protease inhibitor into the normal range (17). These studies therefore support the view that the heparin-antithrombin and protein C-thrombomodulin systems are tonically active regulatory mechanisms that limit prothrombin activation in humans.

Warfarin exhibits a major anticoagulant effect on the vitamin $\mathrm{K}$-dependent procoagulant factors as well as a potential "procoagulant action" on the protein $\mathrm{C}$ anticoagulant mechanism as outlined above. Hence, it was of interest to evaluate drug-induced alterations of hemostatic system activation in patients with congenital deficiencies of antithrombin or protein $\mathrm{C}$. In the antithrombin-deficient subjects, we were able to show that the imbalance between procoagulant and anticoagulant forces could be corrected with warfarin therapy. However we observed that many of these patients exhibited plasma $F_{1+2}$ levels at a given PT ratio that were substantially elevated as compared with anticoagulated individuals without an inherited thrombotic disorder. Normalization of the concentrations of antithrombin in three patients with congenital deficiencies of the protease inhibitor resulted in a further substantial decrease in the plasma levels of $F_{1+2}$. We speculate that the apparent resistance to warfarin is secondary to an augmented "procoagulant effect" of the drug on the protein C anticoagulant mechanism that is usually masked by the normal functioning of the endogenous heparan sulfate-antithrombin anticoagulant pathway. The markedly suppressed plasma concentrations of $F_{1+2}$ observed in a few of the antithrombin-deficient subjects could potentially be related to increases in the plasma level of the protease inhibitor that have been observed in occasional individuals with this disorder receiving oral anticoagulants (50). 
An enhanced "procoagulant effect" of warfarin on the protein $\mathrm{C}$ anticoagulant pathway as was observed in patients with antithrombin deficiency might also be expected in individuals with congenital protein $\mathrm{C}$ deficiency. However, we noted that the relationship between the suppression of prothrombin activation as measured by the $F_{1+2}$ assay and the PT ratio in anticoagulated subjects with protein $\mathrm{C}$ deficiency was identical to that which was observed in individuals without an inherited thrombotic disorder. These data imply that the chronic administration of warfarin leads to a dominant anticoagulant effect on the vitamin $\mathrm{K}$-dependent procoagulant factors of the hemostatic system as compared with the "procoagulant action" of the drug on the protein C anticoagulant mechanism when the endogenous heparan sulfate-antithrombin anticoagulant pathway is functioning normally.

It is apparent from the above investigations that sensitive immunochemical tools such as the $F_{1+2}$ assay are able to assess the overall balance between procoagulant and anticoagulant mechanisms in the circulation of patients with thrombotic diatheses receiving oral anticoagulants. Recent clinical studies have demonstrated that low intensity regimens of warfarin provide prophylaxis against venous thrombosis, but the minimal level of oral anticoagulants required in a given patient remains to be determined. The techniques utilized in this communication may be useful in monitoring the in vivo action of low intensity warfarin therapy in clinical trials designed to establish the lowest amount of this medication needed to protect against a thrombotic event. This more sophisticated assay approach may be particularly helpful because of the potential heterogeneity in patient responses to low intensity warfarin regimens depending on the intrinsic activity of the endogenous heparan sulfate-antithrombin anticoagulant pathway.

\section{Acknowledgments}

We thank Drs. Paul Friedman and Craig Przysiecki for their assistance in the preparation and characterization of partially carboxylated $F_{1+2}$. We are also appreciative of the helpful discussions with Drs. Bruce and Barbara Furie.

This work was supported in part by the National Institutes of Health grant P01 HL-33014.

\section{References}

1. Esmon, C. T., and W. G. Owen. 1981. Identification of an endothelial cell cofactor for thrombin-catalyzed activation of protein C. Proc. Natl. Acad. Sci. USA. 78:2249-2252.

2. Owen, W. G., and C. T. Esmon. 1981. Functional properties of an endothelial cell cofactor for thrombin-catalyzed activation of protein C. J. Biol. Chem. 256:5532-5535.

3. Esmon, N. L., W. G. Owen, and C. T. Esmon. 1982. Isolation of a membrane-bound cofactor for thrombin-catalyzed activation of protein C. J. Biol. Chem. 257:859-864.

4. Kisiel, W. 1979. Human plasma protein C. Isolation, characterization, and mechanism of activation by alpha thrombin. J. Clin. Invest. 64:761-769.

5. Vehar, G. A., and E. W. Davie. 1980. Preparation and properties of bovine factor VIII (antihemophilic factor). Biochemistry. 19:410416.

6. Kisiel, W., W. M. Canfield, L. H. Ericsson, and E. W. Davie. 1977. Anticoagulant properties of bovine plasma protein $C$ following activation by thrombin. Biochemistry. 16:5824-5831.

7. Walker, F. J. 1981. Regulation of activated protein C by protein
S: the role of phospholipid in factor Va inactivation. J. Biol. Chem. 256:11138-11131.

8. Gardiner, J. E., M. A. McGann, C. W. Berridge, C. A. Fulcher, T. S. Zimmerman, and J. H. Griffin. 1984. Protein S as a cofactor for activated protein $\mathrm{C}$ in plasma and in the activation of purified factor VIII:C. Circulation. 70:II-205. (Abstr.)

9. Marcum, J. A., L. Fritze, S. J. Galli, G. Karp, and R. D. Rosenberg. 1983. Microvascular heparinlike species with anticoagulant activity. Am. J. Physiol. 245:H725-H733.

10. Marcum, J. A., J. B. McKenney, and R. D. Rosenberg. 1984. Acceleration of thrombin-antithrombin complex formation in rat hindquarters via heparinlike molecules bound to the endothelium. $J$. Clin. Invest. 74:341-350.

11. Marcum, J. A., D. H. Atha, L. M. S. Fritze, P. Nawroth, D. Stern, and R. D. Rosenberg. 1986. Cloned bovine aortic endothelial cells synthesize anticoagulantly active heparan sulfate proteoglycan. $J$. Biol. Chem. 261:7507-7517.

12. Lau, H. K., J. S. Rosenberg, D. L. Beeler, and R. D. Rosenberg. 1979. The isolation and characterization of a specific antibody population directed against the prothrombin activation fragments $F_{2}$ and $\mathrm{F}_{1+2}$. J. Biol. Chem. 254:8751-8761.

13. Teitel, J. M., K. A. Bauer, H. K. Lau, and R. D. Rosenberg. 1982. Studies of the prothrombin activation pathway utilizing radioimmunoassays for the $F_{2} / F_{1+2}$ fragment and thrombin-antithrombin complex. Blood. 59:1086-1097.

14. Bauer, K. A., B. L. Kass, D. L. Beeler, and R. D. Rosenberg. 1984. The detection of protein C activation in humans. J. Clin. Invest. 74:2033-2041.

15. Nossel, H. L., I. Yudelman, R. E. Canfield, V. P. Butler, Jr., K. Spanondis, G. D. Wilner, and G. D. Qureshi. 1974. Measurement of fibrinopeptide A in human blood. J. Clin. Invest. 54:43-53.

16. Nossel, H. L., M. Ti, K. L. Kaplan, K. Spanondis, T. Soland, and V. P. Butler Jr. 1976. The generation of fibrinopeptide A in clinical blood samples. Evidence for thrombin activity. J. Clin. Invest. 58:1136-1144.

17. Bauer, K. A., T. L. Goodman, B. L. Kass, and R. D. Rosenberg. 1985. Elevated factor Xa activity in the blood of asymptomatic patients with congenital antithrombin deficiency. J. Clin. Invest. 76:826-836.

18. Owen, C. A., Jr., E. J. W. Bowie, and J. H. Thompson, Jr. 1975. The Diagnosis of Bleeding Disorders. 2nd ed. Little, Brown and Company, Boston. 300 pp.

19. Bauer, K. A., J. B. Ashenhurst, J. Chediak, and R. D. Rosenberg. 1983. Antithrombin "Chicago": A functionally abnormal molecule with increased heparin affinity causing familial thrombophilia. Blood. 62:1242-1250.

20. Bertina, R. M., A. W. Broekmans, I. K. van der Linden, and K. Mertens. 1982. Protein C deficiency in a Dutch family with thrombotic disease. Thromb. Haemostasis. 45:237-241.

21. Bertina, R. M., A. van Wijngaarden, J. Reinalda-Poot, S. R. Poort, and V. J. J. Bom. 1985. Determination of plasma protein S: the protein cofactor of activated protein C. Thromb. Haemostasis. 53:268-272.

22. Poser, J. W., and P. A. Price. 1979. A method for decarboxylation of gamma-carboxyglutamic acid in proteins. J. Biol. Chem. 254:431-436.

23. Tuhy, P. M., J. W. Bloom, and K. G. Mann. 1979. Decarboxylation of bovine prothrombin fragment 1 and prothrombin. Biochemistry. 18:5842-5848.

24. Hauschka, P. V. 1977. Quantitative determination of gammacarboxyglutamic acid in proteins. Anal. Biochem. 80:212-223.

25. Fernlund, P., and J. Stenflo. 1983. Beta-hydroxyaspartic acid in vitamin K-dependent proteins. J. Biol. Chem. 258:12509-12512.

26. Hughes, G. J., K. H. Winterhalter, E. Boller, and K. J. Wilson. 1982. Amino acid analysis using standard high performance liquid chromatography equipment. J. Chromatogr. 235:417-426.

27. Friezner Degen, S. J., R. T. A. MacGillivray, and E. W. Davie. 1983. Characterization of the complementary deoxyribonucleic acid 
and gene coding for human prothrombin. Biochemistry. 22:20872097.

28. Greenwood, F. C., W. M. Hunter, and J. S. Glover. 1963. The preparation of ${ }^{131} \mathrm{I}$-labelled human growth hormone of high specific radioactivity. Biochem. J. 89:114-123.

29. Rodbard, D. 1974. Statistical quality control and routine data processing for radioimmunoassays and immunoradiometric assays. Clin. Chem. 20:1255-1270.

30. Rodbard, D., R. H. Lenox, H. L. Wray, and D. Ramseth. 1976. Statistical characterization of the random errors in the radioimmunoassay dose-response variable. Clin. Chem. 22:350-358.

31. Zar, J. H. 1974. Biostatistical Analysis. Prentice Hall, Inc., Englewood Cliffs, NJ. 620pp.

32. Bauer, K. A., L. M. Weiss, D. Sparrow, P. S. Vokonas, and R. D. Rosenberg. 1987. Aging associated changes in indices of thrombin generation and protein $\mathrm{C}$ activation in humans. J. Clin. Invest. 80:1527-1534.

33. Friedman, P. A., R. D. Rosenberg, P. V. Hauschka, and A. Fitz-James. 1977. A spectrum of partially carboxylated prothrombins in the plasmas of coumarin-treated patients. Biochim. Biophys. Acta. 494:271-276.

34. Esnouf, M. P., and C. V. Prowse. 1977. The gamma-carboxy glutamic acid content of human and bovine prothrombin following warfarin treatment. Biochim. Biophys. Acta. 490:471-476.

35. Fernlund, P., J. Stenflo, P. Roepstorff, and J. Thomsen. 1975. Vitamin K and the biosynthesis of prothrombin. J. Biol. Chem. 250:6125-6133.

36. Tans, G., J. W. P. Govers-Riemslag, J. L. M. L. van Rijn, and J. Rosing. 1985. Purification and properties of a prothrombin activator from the venom of Notechis scutatus. J. Biol. Chem. 260:9366-9372.

37. Reeve, E. B., B. Leonard, S. H. Wentland, and P. Damus. 1980. Studies with ${ }^{131}$ I-labelled antithrombin III in dogs. Thromb. Res. 20:375-389.

38. Nosslin, B. 1973. Analysis of disappearance time-curves after sngle injection of labelled proteins. Ciba Found. Symp. 9:113-130.

39. Hull, R., T. Delmore, E. Genton, J. Hirsh, M. Gent, D. Sackett, D. McLoughlin, and P. Armstrong. 1979. Warfarin sodium versus low-dose heparin in the long-term treatment of venous thrombosis. $N$. Engl. J. Med. 301:855-858.

40. Hull, R., T. Delmore, C. Carter, J. Hirsh, E. Genton, M. Gent, G. Turpie, and D. McLoughlin. 1982. Adjusted subcutaneous heparin versus warfarin sodium in the long-term treatment of venous thrombosis. N. Engl. J. Med. 306:189-194.

41. Hull, R., J. Hirsh, R. Jay, C. Carter, C. England, M. Gent, A. G. G. Turpie, D. McLoughlin, P. Dodd, M. Thomas, G. Raskob, and P. Ockelford. 1982. Different intensities of anticoagulation in the long-term treatment of proximal vein thrombosis. N. Engl. J. Med. 307:1676-1681.

42. Sevitt, S., and N. G. Gallagher. 1959. Prevention of venous thrombosis and pulmonary embolism in injured patients. Lancet. 2:981-989.

43. Francis, C. W., V. J. Marder, C. M. Evarts, and S. Yaukoolbodi. 1983. Two-step warfarin therapy: Prevention of postoperative venous thrombosis without excessive bleeding. J. Am. Med. Assoc. 249:374378.

44. Hirsh, J. 1986. Effectiveness of anticoagulants Semin. Thromb. Hemostasis. 12:21-37.

45. D'Angelo, S. V., P. C. Comp, C. T. Esmon, and A. D'Angelo. 1986. Relationship between protein $C$ antigen and anticoagulant activity during oral anticoagulation and in selected disease states. J. Clin. Invest. 77:416-425.

46. D'Angelo, A., C. T. Esmon, P. C. Comp, C. Boyer, P. M. Mannucci, and S. Vigano-D'Angelo. 1985. The half-life of protein $S$ is much longer than protein C. Blood. 66:349. (Abstr.)

47. Broekmans, A. W., R. G. C. Teepe, F. J. M. v.d. Meer, E. Briet, and R. M. Bertina. 1986. Protein C (PC) and coumarin-induced skin necrosis. Thromb. Res. 6:137. (Abstr.)

48. Friedman, K. D., R. A. Marlar, J. G. Houston, and R. R. Montgomery. 1986. Warfarin-induced skin necrosis in a patient with protein S deficiency. Blood. 68:333. (Abstr.)

49. O'Reilly, R. A., and P. M. Aggeler. 1968. Studies on coumarin anticoagulant drugs: Initiation of therapy without a loading dose. Circulation. 38:169-177.

50. Kitchens, C. S. 1987. Amelioration of antithrombin III deficiency by coumarin administration. Am. J. Med. Sci. 293:403-406. 